\title{
Os efeitos da nova gestão pública na produção de conhecimento científico
}

\author{
Dalva Magro' \\ Marli Dias de Souza Pinto
}

\begin{abstract}
RESUMO
Este artigo apresenta os resultados de um estudo realizado em uma universidade pública do Sul do Brasil tendo como objetivo principal identificar os efeitos do New Public Management (NPM), ou Nova Gestão Pública, na produção de conhecimento científico e no cotidiano dos pesquisadores. Acusado de ser ineficiente, e demasiadamente lento em relação ao atendimento às necessidades dos cidadãos, o modelo tradicional de gestão pública, tanto nos governos como nas universidades, ao longo das últimas décadas, vem sofrendo severas críticas por parte da comunidade em geral e, gradativamente, vêm sendo substituído pelo que se convencionou chamar de Nova Gestão Pública. Este novo modelo de gestão baseia-se na introdução de mecanismos de mercado e na adoção de ferramentas da iniciativa privada que incentivam a competição, na expectativa de melhoria da eficiência e dos índices de produtividade. Tendo as avaliações dos programas de pós-graduação como pano de fundo, este estudo centrou-se na investigação de como os pesquisadores estão reagindo às pressões deste modelo de gestão e quais as consequências deste para a produção de conhecimento. Metodologicamente, trata-se de uma pesquisa exploratório-descritiva, na forma de estudo de caso. Conclui-se que, por tratar-se de uma avaliação com base no desempenho quantitativo da produção acadêmica, esta nova forma de avaliar, aliada às mudanças na gestão interna da instituição estudada, levanta a hipótese do surgimento e consolidação de um novo modelo de gestão, com base na desagregação e na competição, porém sem o componente de incentivo financeiro pessoal.
\end{abstract}

Palavras-chave: Public Management. Managerialismo. Gerencialismo. Universidades.

\section{INTRODUÇÃO}

Estudos sobre o New Public Management (NPM) têm demonstrado que, nas últimas décadas, esta filosofia de administração pública tem sido largamente utilizada nas reformas do Estado e registrado um significativo impacto na profissão docente e na produção de conhecimento científico.

O NPM defende que o setor público deve ser administrado sob os preceitos da administração privada, devendo os impactos das políticas governamentais demonstrarem, além de eficiência, maior eficácia. Os

\footnotetext{
1 Doutora em Ciências Empresariais (UP) Professora da FaculdadeSENAC/Florianópolis. dalva.magro65@gmail.com
} 2 Doutora em Engenharia de Produção eSistemas (UFSC) Professora UDESC/ESAG. marli@marlidias.pro.br 
resultados devem ser medidos por meio de índices de desempenho de forma a criar situações de competitividade, fazendo com que haja disputa, o que leva à melhoria da eficiência produtiva.

Nesse cenário, a profissão de docente ganha real destaque, não só por se tratar de uma profissão intimamente ligada aos governos, mas também porque estes têm visto as universidades como um loco que produz a inovação desejada para o desenvolvimento, fazendo com que o papel docente ganhe novos contornos e responsabilidades. As pesquisas passam a ter um papel importante nas políticas nacionais e as universidades a ocupar um lugar de destaque.

No setor público brasileiro, esse cenário inicia-se formalmente em 1995 quando da segunda Reforma Administrativa do Estado cujo objetivo principal era, segundo as palavras de seu idealizador, "tornar o aparelho do Estado mais eficiente, mais capaz de prestar ou financiar serviços sociais, culturais e científicos, com baixo custo e boa qualidade" (BRESSER-PEREIRA, 2010, p. 178).

Juntamente com o NPM, houve uma busca pelo fortalecimento da função avaliação na gestão governamental, o que levou a uma grande mudança especialmente nas universidades brasileiras. A partir do fim da década de 1990, num esforço para aumentar a inserção internacional das Pós-Graduações brasileiras, a Coordenação de Aperfeiçoamento de Pessoal de Nível Superior (CAPES), agência responsável pela avaliação das pós-graduações no Brasil, optou por mudar substancialmente a forma de avaliação que até então vinha adotando. De fato, a CAPES deixou de avaliar os "cursos" e passou a avaliar os "programas" de pós-graduação.

A avaliação que até então era feita por conceitos alfabéticos passa a computar, além da qualidade do corpo docente, o desempenho do corpo discente, a produção intelectual (nacional e internacional) e a inserção do programa ao nível internacional. No entanto, o maior impacto registrou-se na sequência dos desdobramentos da avaliação que também aprecia a distribuição das publicações entre os docentes do programa, forçando-o a ser coeso e produtivo, podendo a sua classificação ser rebaixada ou até o curso ser descredenciado, caso não se atinja o grau de satisfação desejado.

Toda essa transformação na forma de avaliar os cursos de pós-graduação tem acarretado mudanças substanciais na criação de conhecimento científico no Brasil, no cotidiano dos docentes e na gestão dos cursos de pós-graduação. A avaliação da CAPES tem-se mostrado rigorosa como mostram os resultados do triênio 2007-2009, o que é demonstrado pelo fato de, dos 2.718 programas avaliados, 19\% terem melhorado a sua nota, enquanto 71\% mantiveram e 10\% diminuíram. Mesmo assim, de acordo com a CAPES, o Brasil subiu posições no ranking mundial da produção científica (CAPES, 2010).

Embora os resultados apresentados demonstrem o rigor do sistema de avaliação, existem estudos que questionam os métodos e a forma como o sistema atua, alegando que, por conta dos métodos excessivamente quantitativos, a qualidade pode estar sendo posta em causa, uma vez que os pesquisadores precisam manter/aumentar as suas publicações anuais de forma a manter/aumentar a classificação do programa.

Conhecedores dessas evidências, o que se pretende escrever neste artigo é: Como os pesquisadores brasileiros estão sendo afetados pelo modo de gestão vigente e quais as implicações deste na produção de conhecimento científico? Desse modo, como objetivo principal do estudo pretende-se: identificar os efeitos da Nova Gestão Pública na produção de conhecimento científico e no codiano de pesquisadores.

Este estudo se justifica pelas mudanças que vêm sendo relatadas a respeito dessa filosofia no trabalho docente e na identidade das universidades em outras partes do mundo, e pelo fato de o Brasil, na década de 1990, ter efetuado uma reforma administrativa nos moldes da referida filosofia. Outro motivo para estudar o assunto em foco diz respeito às características das mudanças nas avaliações dos Programas de Pós-Graduação, que passaram a intervir no dia a dia dos docentes, sugerindo a possibilidade de mudanças na identidade e no trabalho destes. A esse respeito, a literatura ainda é incipiente no Brasil. Observou-se que os estudos da maioria dos autores têm privilegiado os impactos quantitativos, não sendo ainda significativos trabalhos qualitativos relatando como as mudanças nas avaliações têm impacto na rotina dos docentes e dos pesquisadores.

Estudar esse assunto, especificamente nesta universidade, pode ajudar a entender como a filosofia do NPM se foi consolidando no meio acadêmico uma vez que ela foi a primeira universidade brasileira a aliar-se ao governo federal nas reformas de gestão em 1995, quando recebeu aporte de recursos oriundos da Financiadora de Estudos e Projetos (FINEP).

Metodologicamente, trata-se uma pesquisa exploratório-descritiva, classificada como estudo de caso, que teve como respondentes professores pesquisadores da Instituição.

A fim de organizar a apresentação dos resultados, o presente artigo encontra-se dividido em cinco seções, 
sendo a primeira referente à introdução. Na segunda seção, apresentam-se, à luz da literatura, estudos teóricos sobre o assunto de pesquisa. Na terceira, detalha-se com maior profundidade o método de coleta e tratamento dos dados. Na quarta seção, analisam-se os dados e interpretam-se os resultados e, na quinta, trata-se das considerações finais.

\section{NEWPUBLICMANAGEMENTEMANAGERIALISMO}

Para entender as mudanças que vêm ocorrendo nas últimas décadas nas universidades brasileiras, é necessário entender as tendências mundiais e as pressões sofridas pelas administrações públicas para a obtenção de maior eficiência, eficácia, qualidade mediante as práticas administrativas do NPM, conjugadas com as práticas managerialistas.

Em termos gerais, neste trabalho o managerialismo refere-se a um modelo conceituado por Lima (1998, p. 73) que

[...] aposta no aumento da qualidade através de ganhos de eficiência interna e do crescimento da produtividade das instituições, o modelo institucional gerencialista emerge vigorosamente, entre discursos políticos, atos legislativos, medidas aparentes avulsas de administração, ganhando adeptos entre setores conservadores e tecnocráticos, dentro e fora das universidades.

Essa nova forma de administrar causou mudanças profundas na gestão pública e, consequentemente, nas universidades públicas, enfatizando uma ruptura com os modelos anteriores nos modos de governação do sistema e das instituições (REED, 2002). Como consequência, isso tornou evidente a redução da gestão acadêmica a questões de eficiência (SANTIAGO; MAGALHÃES; CARVALHO, 2005), buscada por meio de sistemas intrincados de avaliações que congregam métodos finalísticos e institucionais (CUNHA, 2003) impostos pelo Estado Avaliador (AFONSO, 2000) no sentido de melhorar a qualidade e a inserção internacional da pesquisa e da pós-graduação brasileiras.

O Estado passa a adotar um estilo mais competitivo, passando a admitir a lógica de mercado em um modelo de gestão no qual prevalece a ênfase em resultados ou produtos voltados para os interesses da sociedade. A avaliação dos programas de pós-graduação torna-se, assim, um pré-requisito para a introdução dos mecanismos de controle e responsabilização desejados pelo Estado, já que, sem objetivos claros definidos a priori, torna-se impossível criar indicadores e medir o desempenho dos sistemas.

Corroborando a ascensão do managerialismo na produção do conhecimento científico, há a tese dos novos modos de produção de conhecimento (GIBBONS et al., 1994). Com base nesses novos modos, a geração do conhecimento estaria alicerçada nos conceitos de produção, no contexto da aplicação, transdisciplinaridade e controle de qualidade. 0 financiamento das investigações dependeria mais da iniciativa privada do que do governo e das agências de fomento, cujo foco passa a ser a inovação.

No entanto, essa mudança na forma de produzir conhecimento opõe-se ao paradigma Mertoniano, ainda vigente, que defende a noção de autonomia e de neutralidade da ciência, além da ideia de que o pesquisador que busca outros objetivos (por exemplo, contribuir para a resolução de problemas práticos) não faz propriamente ciência. Esse entendimento leva a crer em um conflito filosófico entre os que defendem o NPM e o managerialismo - mais voltado para o mercado com medidas de desempenho alicerçadas na efetividade -, e os mais tradicionais, que defendem a neutralidade da ciência descolada dos imperativos econômicos de mercado.

A inter-relação do NPM e managerialismo com os novos modos de produção de conhecimento (GIBBONS et al., 1994), aliados ao novo sistema de avaliação da CAPES, formarão a base dos conceitos que serão desenvolvidos neste estudo uma vez que, nas últimas décadas, estes se entrelaçaram continuamente em um contexto comum de análise, que é a produção de conhecimento científico nas universidades do país.

Em virtude da introdução da avaliação, do aumento das cobranças por produtividade, da orientação para eficiência e da accountability, alguns dos aspectos do cotidiano profissional, como a autonomia e a carga de trabalho, são afetados (CHANLAT, 2002). As atividades docentes têm mudado nas últimas décadas. Musselin (2007), em pesquisa acerca das transformações do trabalho acadêmico na França, relata que tarefas como elaboração de projetos, desenvolvimento de contratos, elaboração de programas de aprendizagem e/ou outros trabalhos, como transferência de tecnologias, já não são mais consideradas atividades periféricas ou secundárias na profissão acadêmica. 
Sendo assim, tem-se que, com o advento das pós-graduações e das pesquisas, a carreira docente incorporou outras responsabilidades, ou seja, a de criar conhecimento. Com isso, veio também a necessidade das publicações, pois se espera de um docente que não só crie, mas também que repasse o conhecimento criado, colaborando para a formação de novos pesquisadores.

\section{METODOLOGIA}

O estudo foi elaborado com base nos pressupostos da pesquisa de abordagem qualitativa tendo em vista aspectos fundamentais: conceitual, pela busca da compreensão dos significados e das relações subjacentes a situações e fatos descritos (TRIVIÑOS,1987). Trata-se então de um estudo de caso caracterizado por uma pesquisa exploratório-descritiva de natureza qualitativa, pois busca proporcionar melhor entendimento sobre as variáveis que fazem parte do fenômeno (THEODORSON; THEODORSON, 1970). A investigação ocorreu por meio de uma análise intensiva do contexto de um fenômeno contemporâneo, evidenciando os seus pressupostos e atribuições (YIN, 2005).

Como pesquisa exploratória, define-se o que propõe Malhotra (2005, p. 125) de que "o objetivo é explorar ou examinar um problema ou situação para proporcionar conhecimento e compreensão". Com o propósito de identificar os efeitos da Nova Gestão Pública na produção de conhecimento científico e no cotidiano de pesquisadores, também esta pesquisa se define como pesquisa descritiva, pois está se buscando determinar as respostas para as perguntas quem, o quê, quando, onde e como (ZIKMUND, 2006).

Salienta-se que se trata de um estudo de caso único, pois abrangeu a pesquisa de uma universidade pública do Estado de Santa Catarina; assim sendo, caracteriza-se como estudo de caso sedimentado pelo que apregoa Yin (2005, p. 32) que é a "investigação empírica que investiga um fenômeno contemporâneo dentro de seu contexto, da vida real, especialmente quando os limites entre o fenômeno e o contexto não estão claramente definidos".

Para a coleta de dados do estudo de caso, esta pesquisa tem sua validade embasada, de acordo com o que preconiza Yin (2005), pela utilização de várias fontes de evidências, de tal forma que incentive linhas convergentes de investigação, igualmente deve se estabelecer o encadeamento das evidências.

Como instrumento de coleta de dados, utilizou-se a entrevista, que pode ser definida por Flick (2009) como um instrumento no qual são feitas perguntas embasadas na teoria e direcionadas para as hipóteses.

Os entrevistados foram escolhidos pelo critério de ser docente pesquisador com experiência em pesquisa que varia entre dez e 33 anos ligado aos programas de pós-graduação reconhecidos e avaliados pela CAPES. Na pesquisa, teve-se o cuidado de entrevistar pesquisadores de cursos com maior e menor interação com o mercado. Essa separação se faz necessária dado o NPM ter suas bases filosóficas fundadas nas práticas de gestão oriundas do mercado.

\section{RESULTADOSDA PESQUISA}

A entrevista foi dividida em duas partes. Na primeira delas, foi investigada a percepção docente das mudanças ocorridas nas últimas décadas no processo de fazer pesquisa científica em uma universidade. Cientes das mudanças, a etapa seguinte foi investigar as consequências destas para a produção do conhecimento.

\subsection{Percepções docentes das mudanças ocorridas no processo de produção de conhecimento científico}

As influências do sistema de avaliação no dia a dia docente são muitas e variadas, podendo citar-se como exemplo necessidade de publicações qualificadas, maior accountability, ampliação da carga de trabalho, diminuição da liberdade individual e aumento do controle institucional. Todos esses imperativos se entrelaçam num emaranhado de outras pequenas dificuldades que levarão a uma mudança na identidade dos docentes, pois que o foco da profissão está deixando de ser a transmissão do conhecimento para ser, sobretudo, a produção deste. 
Conhecendo essas variáveis, a partir daqui, analisou-se cada uma delas em separado, para assim compor o puzzle dos impactos causados pelo NPM nas pesquisas.

A necessidade de publicação se justifica pela forma com que os programas de pós-graduação são avaliados e apresenta tal grau de pressão, que ficou constatado não ser mais as avaliações da CAPES a pressionar. Segundo os investigados, a pressão está no próprio colega do lado, que está sempre a perguntar: “- Já escreveu o artigo?" "Já mandou o material pra não sei onde?" "O que eles responderam?". o prazer de sentar, tomar um cafezinho e falar algumas amenidades nos intervalos está deixando de existir. A cobrança e a pressão estão dentro da instituição, dentro do programa, de forma ininterrupta. 0 trabalho de cada um impacta na avaliação do programa e as cobranças acontecem o tempo todo.

Cabe salientar que a necessidade de produção é uma exigência do sistema de avaliação dos programas de pós-graduação (CAPES, 2008), pois dessa avaliação depende a quantidade de bolsas que o programa receberá, bem como as oportunidades para os alunos concorrerem a bolsas e a intercâmbios internacionais.

De outra forma, o aumento de produção pode ser analisado, igualmente, em decorrência das pressões por produção qualificada. Conforme foi relatado pelos pesquisadores, ele está ocorrendo também por uma mudança de postura dos pesquisadores, que optam por aumentar o número de publicações, fazendo-o por meio da fragmentação de artigos. A justificativa e aceitação dessa prática está no entendimento corrente de que os artigos são publicados com pequenas contribuições para o conhecimento e não mais com grandes inventos a mudar a humanidade.

Essa forma de entender o conhecimento parece coincidir com o Modo 2 de produção de conhecimento (GIBBONS et al., 1994), no qual este é fruto do trabalho colaborativo da heterogeneidade e diversidade organizacional, em que o todo é composto pela soma das competências agregadas. Porém, o entendimento de trabalho colaborativo e criação de conhecimento coletivo acabou por ser adaptado à realidade da alta produtividade, dando margem para o entendimento de que tudo deve ser publicado. Assim, no âmbito da pesquisa, o que deveria ser um único projeto, que no fim geraria uma reflexão de como e por que aconteceu, acaba por se desdobrar, na verdade, em diversas publicações no período, com pequenas reflexões das etapas e do andamento do que vai acontecendo, para, assim, existir uma alta especialização.

Nessa direção, a fim de preservar a qualidade das pesquisas brasileiras, a CAPES se utiliza da ferramenta Qualis como auxílio para que não haja a proliferação e até a banalização na produção de artigos ditos científicos, considerando nas avaliações somente publicações qualificadas. Esse procedimento, de certa forma, ajuda a fortalecer a qualidade do sistema avaliativo, mas não garante que as demais publicações deixem de ocorrer. A responsabilidade do que é ou não publicável recai sobre o corpo editorial das revistas e periódicos que, por sua vez, também estão sofrendo pressões.

0 resultado dessa proliferação de artigos, como previa Chanlat (2002), foi o aumento da carga de trabalho. De acordo com as entrevistas, para um docente - mesmo que tenha contrato de trabalho de quarenta horas semanais -, é impossível trabalhar menos de sessenta horas, visto que o trabalho não alocado em planilha de ocupação docente é árduo e extenso.

Para um pesquisador que trabalha ligado a um programa de pós-graduação, além do seu trabalho rotineiro de dar aulas, orientar alunos, pesquisar, elaborar relatórios, escrever artigos e participar de congressos, existe ainda a necessidade de estar no circuito das avaliações e das bancas de mestrado e doutorado. Para isso, é necessária a leitura da dissertação ou da tese, a avaliação e, posteriormente, o tempo de deslocamento para participar da defesa. Esse tipo de trabalho não é alocado em planilha, pois se trata de trabalho prestado à outra instituição, que acaba por não remunerá-lo.

Do modo como está estruturado o sistema, também se torna impossível recusar o convite para participar das bancas examinadoras. Isso porque, quando seu programa necessita de um avaliador externo, dificilmente encontrará alguém disponível se não houver colaboração entre programas. Quando questionados a respeito da falta de remuneração por tais tarefas, uma vez que estariam sendo realizadas fora da planilha de ocupação docente, foi apontada a dificuldade ética e filosófica existente em se aceitar, no meio acadêmico, que um docente receba alguma remuneração por uma avaliação, pelo entendimento de que, se houvesse tal remuneração, a avaliação poderia ser menos rigorosa.

A diminuição da liberdade individual e aumento do controle institucional é observada no grau de cobrança, que, segundo os entrevistados, atualmente, é infinitamente maior do era há uma década, tendo aumentado também o controle. Nesse sentido, para que um projeto seja aprovado, faz-se necessário passar por diversas instâncias e ser submetido a uma série de crivos. A lógica não deixa de ser correta, porque é meritocrática, mas, 
tem-se também um efeito colateral: o ambiente competitivo acaba por privilegiar os cientistas com maior qualificação (SCHWARTZMAN, 2008), excluindo ou segregando aqueles pesquisadores mais jovens e com menor experiência que pretendem entrar no sistema, fazendo com que percam a motivação para a pesquisa.

A accountability pode ser entendida como a prática de prestar contas e assumir responsabilidades perante os cidadãos, com objetivo de criar transparência e, consequentemente, aumentar a confiança. Na produção de conhecimento, esse entendimento está alinhado com o que Campos (1990) denomina de responsabilidade subjetiva, quer dizer, a cobrança que a pessoa faz de si mesma relativamente à prestação de contas de seus atos a alguém. Esse sentimento está atrelado ao fato de os pesquisadores terem a noção de que os recursos para pesquisa, em sua grande maioria, advêm de recursos públicos e necessitam ser justificados.

Com o advento de leis, como a de Responsabilidade Fiscal (BRASIL, 2000), e todo o aparato criado em torno desta, a necessidade de uma accountability mais ampla está presente em todas as instâncias do setor público. Não somente os pesquisadores, mas toda a cadeia da produção científica está sentindo seus efeitos.

No meio acadêmico, a accountability está a ser percebida nas cobranças por prestações de contas mais detalhadas, exigência de publicações em revistas qualificadas, sendo atualmente muito maior do que era há uma década.

Cientes de como os pesquisadores estão percebendo as mudanças ocorridas nas últimas décadas no ambiente científico, passa-se agora a relatar as implicações das mudanças na produção de conhecimento.

\subsection{Implicações para a produção de conhecimento científico}

É fato que a CAPES está fazendo um ótimo trabalho no que concerne à avaliação dos cursos de pósgraduação no Brasil. Ela tem tido resultados extraordinários, ao estabelecer parâmetros de qualidade para a pós-graduação brasileira, sendo inclusive considerado o melhor sistema avaliativo da América Latina, comparável ou até superior ao de muitos países desenvolvidos (SCHWARTZMAN, 2008). Por sua vez, o Conselho Nacional de Desenvolvimento Científico e Tecnológico (CNPq) tem direcionado seus esforços para o aumento das bolsas de produtividade científica e exigido como contrapartida maior transparência na avaliação dos pesquisadores (NOVAES, 2008).

Também é fato que a reforma gerencial do estado brasileiro, segundo palavras de seu idealizador, o professor Bresser-Pereira (1995; 2010), baseou-se na responsabilização, na competição administrada por excelência, na responsabilização social e na auditoria de resultados, metodologia largamente utilizada na avaliação dos programas de pós-graduação.

O uso sistemático de indicadores de produtividade acadêmica, combinado com procedimentos de revisão por pares, é apontado por Schwartzman (2008) como um dos pontos fortes do sistema de avaliação brasileiro. No entanto, não se deve deixar de levar em conta os ensinamentos de Holmstrom e Milgrom (1991) quando dizem que ênfases excessivas em metas quantitativas podem deteriorar a qualidade da pesquisa. Nesse aspecto, as entrevistas mostram que, na percepção dos investigadores, as pesquisas têm perdido em qualidade à medida que seus resultados são publicados de forma fragmentada, distribuídos em diversos artigos tendo como objetivo aumentar o número de publicações para atender aos critérios de avaliação.

Foi relatado, inclusive, que até mesmo internacionalmente já está a ser percebido o comprometimento da qualidade em favor da quantidade, em virtude da diminuição do espaço para publicação permitida pelos periódicos. A necessidade da diminuição do tamanho dos artigos está fazendo com que os relatos dos estudos tenham de ser sintetizados, fazendo com que a discussão fique comprometida.

De forma a verificar esse fato, efetuou-se uma pesquisa no portal de periódicos científicos $A$ to $Z$ EBSCO para observar qual está sendo a tendência dos periódicos (revistas e jornais científicos) no sentido apontado. Iniciou-se a investigação de forma a obter uma linha de tendência do comportamento dos periódicos nos últimos catorze anos em relação ao número de edições publicadas por ano, número de artigos por periódico e número de páginas por artigo. Buscou-se por periódicos que contivessem no título o nome Higher Education. 0 portal disponibilizou 93 periódicos que continham a mencionada informação. Destes selecionaram-se somente os que disponibilizavam uma série de edições com mais de catorze anos. Foram assim selecionados doze periódicos. Um com dados desde 1930, outro 1970, quatro de 1980, um 1990 e cinco de 1995.

Nos resultados da pesquisa, foi possível constatar certa pressão por publicações visto que, dos doze periódicos consultados, somente um (The Journal of Higher Education) não teve o número de edições anuais aumentado nos últimos catorze anos; porém, conforme se verá no decorrer desta análise este periódico 
especificamente está mudando gradualmente sua forma de atuação no meio das publicações científicas.

A evolução dos dados do segmento em questão pode-se observar no Gráfico 1.

Gráfico 1 - Evolução do número de edições do periódico por ano

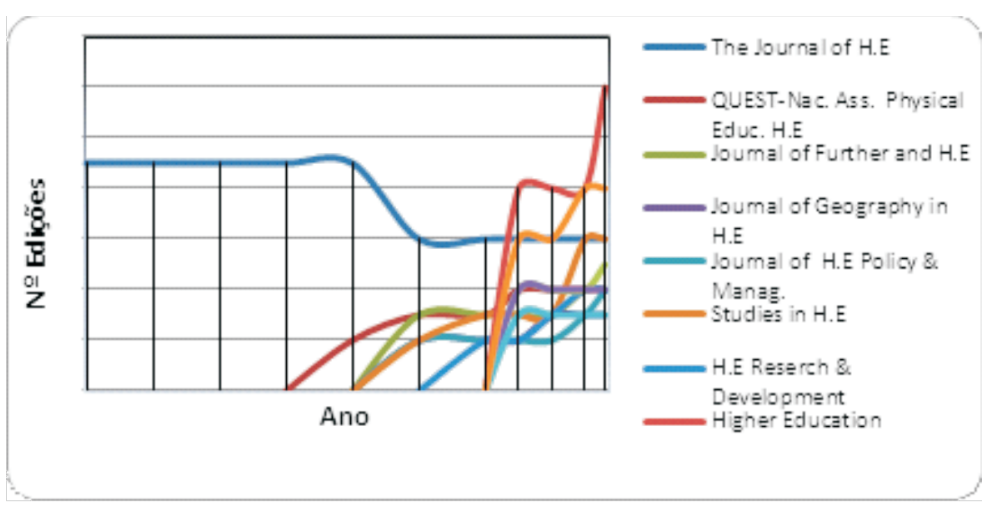

Fonte: Elaborado pelos autores (2012)

Com relação ao número de artigos publicados por edição do periódico, constatou-se que houve uma diminuição; no entanto, nada significativa se for levado em consideração que a maior variação fica em torno de três artigos para menos. As exceções ficam por conta do The Journal of Higher Education, que já havia diminuído o número de edições anuais de nove para seis e agora a de artigos; entretanto, como será visto a seguir, ele vem aumentando o número de páginas por artigo. Já o Quest aumentou o número de edições anuais de duas na década de 1970 para quatro na década de 90, variando um pouco no número de artigos com um grande aumento na década de 70, procurando uma estabilização no início deste século. Essas mudanças podem ser mais bem visualizadas no Gráfico 2 .

Gráfico 2 - Evolução do número de artigos da primeira edição do periódico do ano

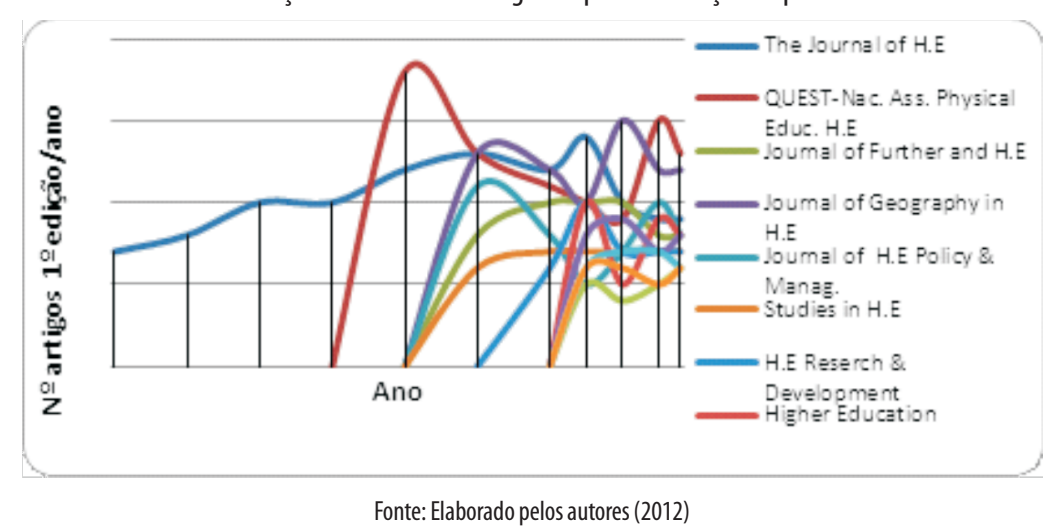

No que se refere à diminuição do número de páginas por artigo - que foi o que deu início a esta investigação -, o fato pode ser comprovado. 0 Gráfico 3 mostra haver realmente uma sensível queda no número de páginas dos artigos científicos verificada mais especificamente nos últimos três anos. 
Gráfico 3 - Evolução do número de páginas por artigo da primeira edição do periódico do ano

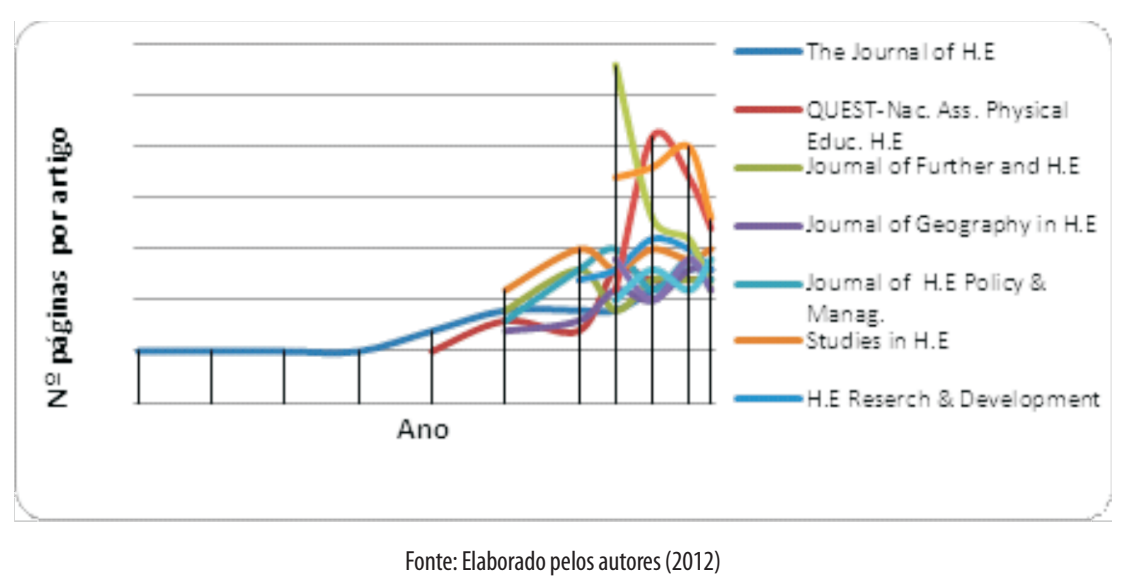

Observando o Gráfico 3, quando analisados os últimos anos (2005 a 2008), pode-se notar que os únicos periódicos que aumentaram o número de páginas por artigo foram: Quality in Higher Education e Studies in H.E, de onze para catorze e de catorze para quinze, respectivamente. Contudo, não se pode afirmar que seja uma tendência, pois o número de páginas desses periódicos segue os demais que apresentam oscilação entre dez e quinze páginas por artigo. Os periódicos que demonstraram uma oscilação maior no número de páginas por artigo foram o Research in Higher Education, Higher Education, Inovative in Higher Education; demonstrando, porém, uma tendência de adequação aos demais.

Do comportamento dos periódicos, pode-se concluir que: (i) o número de periódicos em Higher Education é grande, (93 títulos); no entanto, apenas doze apresentaram uma série de dados com mais de catorze anos, o que leva a concluir que o mercado editorial na área tem aumentado nos últimos vinte anos; (ii) o número de edições anuais, das doze revistas, aumentou o que corrobora a tese do aumento do mercado de publicações; (iii) o número de artigos por periódico diminuiu; porém, não na proporção em que as edições aumentaram, porque, na realidade quando computados os números totais de artigos, tem-se que em 1995 foram publicados, em média, pelos doze periódicos pesquisados, 411 artigos e, em 2008, quinhentos artigos. Conclui-se, então, que a diminuição do número de artigos por periódico não diminuiu o número total de artigos publicados; e, (iv) o número de páginas por artigo, que na maioria dos periódicos oscilava entre sete e quinze em 1990, aumentando para dez e quinze de 1995 a 2005, volta a diminuir nos três últimos anos, onze a treze páginas. Dos doze periódicos pesquisados entre 2005 e 2008, metade deles diminuiu o número de páginas por artigo, 30\% vêm mantendo inalterado e $20 \%$ aumentaram o número de páginas.

De todo o exposto, percebe-se estar de fato havendo uma maior pressão por número de publicações, tanto que as revistas estão aumentando o número de edições e artigos publicados. Se esse comportamento é decorrente da filosofia do NPM, da gestão managerialista e do Estado Avaliador, que se utilizam de índices de citações para medir a qualidade e a efetividade das IES, das investigações e dos investigadores, ainda não se pode afirmar; entretanto, uma tendência nesse sentido já pode ser percebida.

Seguindo com a análise das implicações do NPM para a produção de conhecimento, os pesquisadores afirmam fazer as pesquisas com qualidade, porém dentro do que o sistema permite, sem, no entanto, deixar de ter a sensação de que poderiam fazê-la melhor. Como consequência, pode-se apurar certo desestímulo profissional gerado pela angústia de não estarem conseguindo atingir as metas impostas e pela sensação de estar entregando um trabalho antes de ser considerado plenamente terminado. Corroborando tal percepção, tem-se o estudo de Novaes (2008), que aborda os conflitos entre qualidade e quantidade na pesquisa em Economia que conclui haver sinais de que os mecanismos de avaliação do CNPq e da CAPES estejam induzindo a um sacrifício de qualidade para aumentar a quantidade de publicações.

Em outras palavras, a qualidade também foi abordada na necessidade de mensurar a utilidade e aplicabilidade dos projetos de pesquisa gerados no interior de uma instituição pública mantida com recursos oriundos da comunidade. Inclusive sendo questionada a utilização de recursos públicos no desenvolvimento de produtos que venham gerar um impacto social questionável. A crítica nesse sentido foi que se produz muito, 
mas desassociado à aplicabilidade e pouco avaliado no sentido do "socialmente correcto".

Por fim, tem-se a opinião de um dos entrevistados que atua como avaliador do CNPq quando afirma textualmente que na sua área o produto final das investigações ainda demanda por melhoria na qualidade. Porém, a pesquisa mostrou que a qualidade está a ser perseguida, bastando que se encontre um equilíbrio entre as pressões quantitativas e a qualidade desejada, tanto por parte da CAPES, CNPq e universidades, quanto pelos próprios pesquisadores.

De outra forma, a criação de conhecimento, como algo novo, surpreendente, está relativizada na contemporaneidade, dado o entendimento que as grandes descobertas não são mais possíveis de serem feitas por um único indivíduo. As descobertas se traduzem no somatório de grandes redes colaborativas, que gerarão um resultado final, situado para além das fronteiras disciplinares tradicionais, com características multidisciplinar e transdisciplinar. (GIBBONS et al., 1994).

Da pesquisa, pode-se constatar que o entendimento acabou por ser distorcido e adaptado à realidade de alta produtividade e o que deveria ser um projeto de pesquisa, e durar dois anos e depois, talvez, vir a gerar uma reflexão do durante e por que ele aconteceu, acaba por se desdobrar, na verdade, em diversas publicações durante esse tempo. Então, o que se terá, segundo a grande maioria dos entrevistados, é uma grande quantidade de produção que não agrega muito, uma em relação a outra, gravitando sempre sobre o mesmo tema.

A relevância dos temas de pesquisa também está mudando porque, atualmente, encontra-se vinculada ao plano de trabalho do professor e necessita da aprovação dos pares, estar relacionada à vontade da instituição, deixando assim de ser um ato isolado do pesquisador.

Sua aceitação depende da aprovação nas diferentes instâncias de pesquisa, dos comitês de avaliação, dos temas que estão sendo discutidos na academia, da realidade atual e até da própria crise. Os temas de pesquisa passam a ter uma relação direta com os fenômenos que estão em evidência, assim como com aquilo que é tema e que é debate na comunidade cientifica. Nesse sentido, os resultados desta pesquisa demonstram que, se o pesquisador não estiver de acordo com esses imperativos, terá grande dificuldade em publicar seus experimentos e reflexões e, não publicando, também estará fora do sistema de financiamento da pesquisa, por melhor que seja seu projeto, bem como fora dos programas de pós-graduação.

Acrescida à relevância, há, ainda, a liberdade de pesquisa mais restrita. De acordo com os entrevistados, ela existe, mas não é total, porque a avaliação da produção é cumulativa, então, o pesquisador acaba, de alguma maneira, sendo empurrado de forma sutil a ficar restrito a um objeto de pesquisa, dada a produção naquele segmento ser maior e também por ficar mais conhecido como pesquisador daquele objeto e, consequentemente, tendo maiores oportunidades de publicação.

E, por fim, este estudo constatou certa degradação das relações interpessoais, decorrentes da alta competitividade e do excesso de trabalho. Conforme os resultados encontrados, as relações familiares são postas em causa, em detrimento da necessidade de cumprir prazos, ficando as relações pessoais mais restritas às relações de trabalho.

\section{CONSIDERAÇÕES FINAIS}

Este estudo possibilitou um novo olhar sobre a gestão pública e sua interação no universo da produção de conhecimento. Trata-se de um estudo de caso; portanto, restrito à área de estudo; contudo, por ter de considerar as pressões advindas do ambiente no qual a Universidade está inserida e grande parte destas interações serem resultado das pressões externas, este estudo pode servir como base para alguma futura generalização dos resultados.

Por assim ser, de todo o exposto, foi possível fazer a síntese das influências do NPM na produção do conhecimento e traçar um quadro que melhor demonstre a realidade da Universidade estudada e, de certa forma, igualmente das demais universidades brasileiras, nas inter-relações existentes no complexo processo de gestão do conhecimento científico e das influências que este sofre.

Em resumo, as mudanças na produção de conhecimento científico mais percebidas pelos investigadores dizem respeito primordialmente à avaliação dos programas de pós-graduação que está baseada na produção docente; na necessidade de publicações qualificadas; na fragmentação dos artigos de forma a obter maior número de publicações; no aumento da carga de trabalho e no aumento da competição. 
Na Figura 1, podem-se verificar as inter-relações entre as novas formas de relacionamento das universidades, governo e sistemas de avaliação, assim como as transformações ocorridas e as implicações para a produção de conhecimento.

Figura 1 - Nova forma de visualizar as inter-relações das variáveis que interagem no processo de produção do conhecimento científico

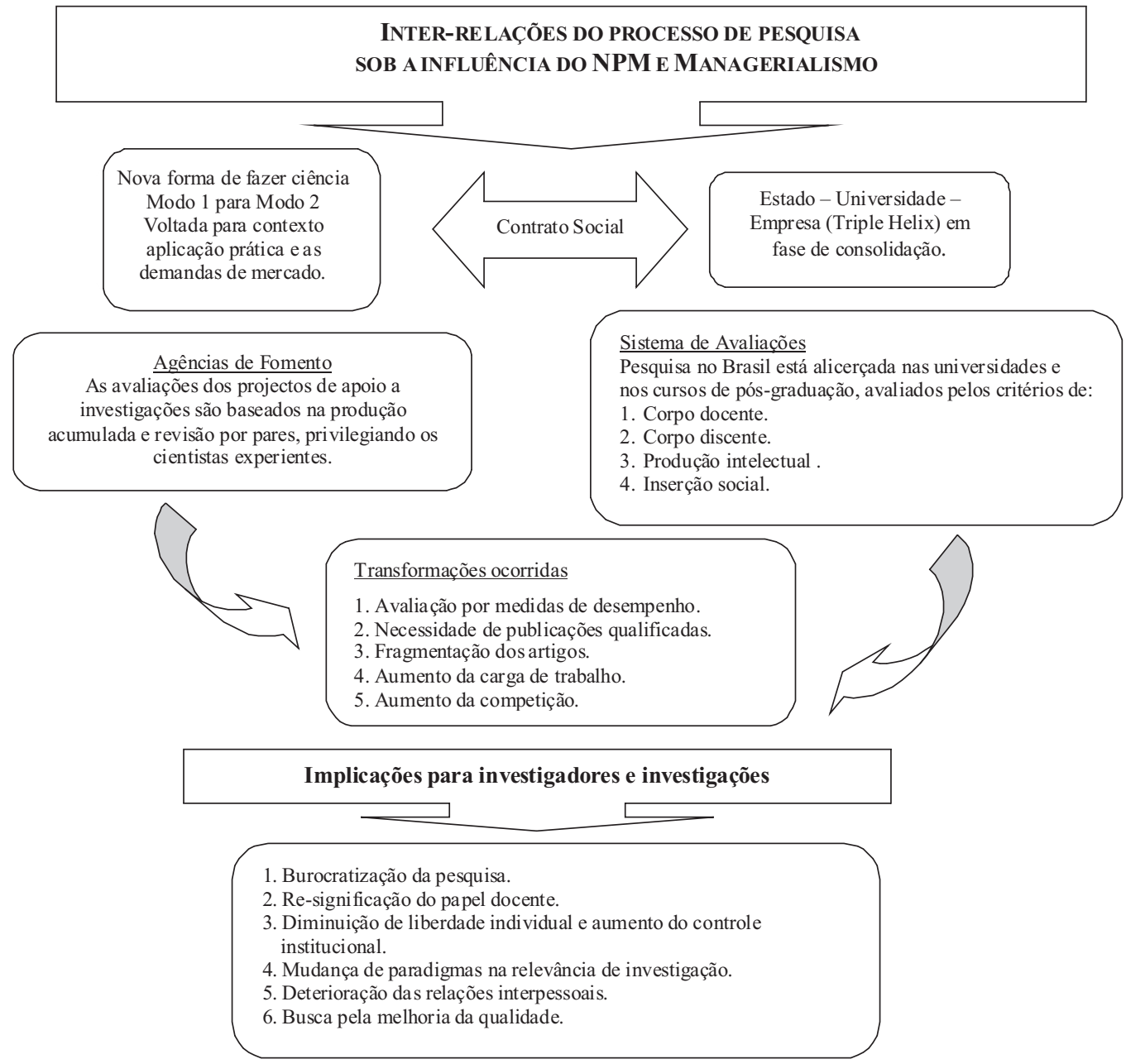

Fonte: Elaborado pelos autores (2012)

Como consequências desses imperativos têm-se: a burocratização da pesquisa como consequência da accountability; a re-significação do papel docente na especialização dos investigadores em obter recursos para pesquisa por meio de projetos; a diminuição da liberdade individual em detrimento do aumento do controle institucional; a mudança dos paradigmas da relevância das pesquisas em virtude dos pressupostos das avaliações; a deterioração das relações interpessoais pelo aumento das pressões por publicações e da maior competição e a busca pela melhoria da qualidade que ainda é considerada como deficiente. 


\title{
THE EFFECTS OF THE NEW PUBLIC MANAGEMENT ON THE PRODUCTION OF SCIENTIFIC KNOWLEDGE
}

\begin{abstract}
This article presents the results of the study carried out in a southern Brazil public university and its main goal is to identify the effects of the New Public Management - NPM in the production of scientific knowledge and their researchers' daily lives. The traditional model of public administration has been pointed out as inefficient and too slow to fulfill the citizen needs, both in government and in universities, over recent decades, has come under severe criticism from all community and, gradually, has been replaced by so-called New Public Management. This New management model is based on the introduction of market mechanisms and adoption of private sector tools that encourage competition in the hope of improving the efficiency and productivity levels. Against the backdrop of the graduate programs evaluation, this survey has focused on the investigation of how researchers are responding to the pressures of this management model and what consequences for the production of knowledge. Methodologically, it is a descriptive exploratory research in case study format. We conclude that, because it is an assessment grounded on quantitative performance of academic production, this new way of evaluating, coupled with changes in the internal management of the institution studied, raises the possibility of the emergence and consolidation of a new management model based on disaggregation and competition but without the personal financial incentive component.
\end{abstract}

Keywords: Public Management. Managerialism. Gerencialismo. Universities.

\section{REFERÊNCIAS}

AFONSO, A. J. Avaliação educacional: regulação e emancipação para uma sociologia das políticas avaliativas contemporâneas. São Paulo: Cortês, 2000.

BRASIL. Lei Complementar n. 101, de 4 de maio de 2000. Estabelece normas de finanças públicas voltadas para a responsabilidade na gestão fiscal e dá outras providencias. Disponível em: <http://www.planalto.gov.br/ccivil_03/leis/lcp/lcp101.htm>. Acesso em: 4. set. 2012.

BRESSER-PEREIRA, L.C. A reforma do aparelho do Estado e a Constituição de 1988 - texto para discussão. Revista del CLAD Reforma y Democracia, n. 1, p. 7-24, 1995.

BRESSER-PEREIRA, L. C. . Os primeiros passos da reforma gerencial do Estado de 1995. In: D'INCAO, Maria Angela; MARTINS, Hermínio (Org.). Democracia, Crise e Reforma: Estudos sobre a Era Fernando Henrique Cardoso. São Paulo: Paz e Terra, 2010. p. 171-212.

CAPES - COORDENAÇÃO DE APERFEIÇOAMENTO DE PESSOAL DE NÍVEL SUPERIOR. Critérios de Avaliação da Área de Administração e Turismo (Triênio 2004-2006). [2008]. Disponível em: <http://www.capes.gov.br/images/stories/download/ avaliacaotrienal/doc_areas_trienal_ 2007/2007_Administracao_Aval2004-2006.pdf>. Acesso em: 12 dez. 2008.

CAPES - COORDENAÇÃO DE APERFEIÇOAMENTO DE PESSOAL DE NÍVEL SUPERIOR. Relatório de Divulgação dos Resultados da Avaliação Trienal 2010. [2010].

<http://trienal.capes.gov.br/wpontent/uploads/2010/09/relatorio_geral_dos_resultados_da_avaliacao.pdf>. Acesso em: 20 out. 2010.

CAMPOS, A. M. Accountability: quando poderemos traduzi-la para o português? Revista de Administração Pública, v. 24, p. 30-50, 1990. 
CHANLAT, J. F. 0 gerencialismo e a ética do bem comum: a questão da motivação para o trabalho nos serviços públicos. In: Congreso Internacional del CLAD sobre la Reforma del Estado y de la Administración Pública, 7., 2002, Lisboa. Anais... Lisboa: [S.n.], 2002. p. 8-11.

CUNHA, L.A. Ensino Superior e Universidade no Brasil In: LOPES, M.E; FARIA FILHO, L.M; VEIGA, G.C (Org.). 500 Anos de educação no Brasil. 3. ed. Belo Horizonte: Autêntica, 2003. p. 151-204.

FLICK, U. Introdução à pesquisa qualitativa. 3. ed. Porto Alegre: Artmed, 2009.

GIBBONS, M. e C. et al. The New Production of Knowledge: The Dynamics of Science and Research in Contemporary Societies. Londres: Sage, 1994.

HOLMSTROM, B.; P. MILGROM. Multitask principal-agent analyses: Incentive contracts, asset ownership and job design. Journal of Law, Economics and Organization, vol.7, n.1, 1991, p.24-51.

LIMA, L.C., Universidade Portuguesa: Notas sobre a crise institucional. In: MOROSINI, Marília C. (Org.).

MERCOSUL/MERCOSUR: Políticas e ações universitárias. Porto Alegre: Autores Associados, 1998. p.179-194

MALHOTRA, N. K. Introdução à pesquisa de marketing. São Paulo: Pearson Prentice Hall do Brasil, 2005.

MUSSELIN, C. The transformation of academic work: Facts and analysis. Califórnia: Center for Studies In Higher Education, 2007. Disponível em:

<http://cshe.berkeley.edu/publications/docs/ROP.Musselin.4.07.pdf>. Acesso em: 26 set. 2012.

NOVAES, W. Pesquisa em economia no Brasil: Uma avaliação empirica dos conflitos entre quantidade e qualidade. RBE, Rio de Janeiro, v. 62, n. 4, p.467-495, out./dez. 2008.

REED, M. New Managerialism, professional power and organizational governance in UK universities: a review and assessment. In: AMARAL, Alberto; JONES, Glen A.; KARSETH, Berit. (Org.). Governing Higher Education: National Perspectives on Institutional Governance. Dordrecht: Kluwer Academic Publishers, 2002. p. 163-186.

SANTIAGO, R; MAGALHÃES, A; CARVALHO, T. A emergência do managerialismo no sistema e nas instituições de ensino superior. Coimbra: Fundação das Universidades Portuguesas, 2005.

SCHWARTZMAN, S. Pesquisa universitária e inovação no Brasil: Avaliação das políticas de ciência e tecnologia e inovação: diálogo entre experiências internacionais e brasileiras. Brasília: Centro de Gestão e Estudos Estratégicos, 2008.

THEODORSON, G.A.; THEODORSON, A. G. A Modern Dictionary of Sociology. Londres: Methuen, 1970.

TRIVIÑOS, A. N. S. Introdução à Pesquisa em Ciências Sociais. São Paulo: Atlas, 1987.

ZIKMUND.W.G. Princípios da pesquisa de Marketing. São Paulo: Pioneira Thomson Learning, 2006.

YIN, R. Estudo de caso: planejamento e métodos. 3. ed. Porto Alegre: Bookman, 2005. 